\title{
Flexure Behaviour of Reinforced High Strength Concrete Elements Affected by Corrosion
}

\author{
Camelia Negrutiu ${ }^{1, *}$, Ioan Sosa ${ }^{1}$, and Bogdan Heghes ${ }^{1}$ \\ ${ }^{1}$ Technical University of Cluj-Napoca, Faculty of Civil Engineering, Cluj-Napoca, 28 Memorandumului St, 400114, Romania
}

\begin{abstract}
Corrosion of the reinforcement is a constant vulnerability for reinforced concrete structures exposed to aggressive environments. High strength concrete is known to prevent corrosion of the reinforcement, in a non-cracked state, when exposed to aggressive environments. The purpose of this study is to assess the opportunity of using high strength concrete in cracked elements exposed to corrosion and compare them with non-exposed elements. A series of simply supported reinforced high strength concrete beams with concrete cover of 25 and $50 \mathrm{~mm}$ were precracked, up to a service life crack of $0.1 \mathrm{~mm}$, further exposed to accelerated corrosion through a process of electrolysis and finally tested to failure. A series of non-exposed witness specimens were also tested to failure. All elements were designed with the same bending capacity. The flexure behaviour was assessed by plotting experimental and theoretical ultimate limit state position of the neutral axis at midspan and the results show no significant differences in the overall behaviour, despite the affected reinforcement, between the corroded and non-corroded elements. Moreover, the design bending moments were approximately $40 \%$ lower than the experimental ones, even for corroded beams, which can be a significant strength reserve of the beams, useful in aggressive environments.
\end{abstract}

\section{Introduction and scope}

The corrosion of the reinforcement poses a serious concern in the service life and durability in reinforced concrete structures, due to the high costs of maintenance and repair. Degradations such as the reduction of the structural loading capacity, accelerated fatigue and increased deformation in service life are common consequences in structures exposed to aggressive environments. Although worldwide researchers have concentrated their efforts in developing effective procedures to evaluate the effects of corrosion, very few structural engineers actually implement durability safety measures. These are the evaluation of the concrete cover as a function of the exposure class and basic concrete composition recommendations expressed in current standards [1].

Reinforced concrete structures present structural cracks in their service life, which are an open path for environmental aggressive agents to reach the reinforcement and initiate corrosion. The initiation and the propagation of corrosion are influenced by the crack width: less than $0.1-0.2 \mathrm{~mm}$ as maximum crack width under static loads is reported not to have a significant impact on the corrosion process; the wider the cracks, the faster the corrosion and the time to failure $[2,3]$. However, micro-cracks developed under alternating loads are increasing the corrosion rate [4]. The thickness of the rust layer on the reinforcement is also correlated to the crack width [5]. Furthermore, the intensity of the current influences the reinforcement section loss. A moderate corrosion rises up to $0.5 \mu \mathrm{A} / \mathrm{cm}^{2}$ which can produce a loss of section of $5.7 \mu \mathrm{m} /$ year and an oxide layering up to $17.3 \mu \mathrm{m} /$ year, whereas stronger corrosion is produced by an intensity current of $1 \mu \mathrm{A} / \mathrm{cm}^{2}$, which corresponds to a maximum of $11.5 \mu \mathrm{m} /$ year and an oxide layering of maximum $34 \mu \mathrm{m} /$ year [6]. Bond deterioration between steel and concrete was found to be a major contributor to the reduction of bending capacity [7]. Ultimate flexural strength decreases proportional to the decrease in the rebar cross-sectional area [8] which is exacerbated by the loading levels [9]. The deformability of the elements is not significantly influenced by the short-term corrosion, but the presence and the distribution of the cracks can facilitate the initiation and progression of the reinforcement corrosion [10]. Corrosion in longitudinal tension reinforcement has a significant negative influence on seismic behaviour [11] and it changes the failure mode to brittle failure and loss of ductility [11, 12]. Corrosion of the stirrups also leads to loss of strength and ductility [13, 14], but stirrup presence can be beneficial on the overall performance [15]. Other reports mention the beneficial influence of the increased concrete cover and low water/cement ratio of the surrounding concrete [15].

High strength concrete is an emerging, innovative, high performance construction material with improved durability resistance. Thick and impermeable concrete cover can stop the initiation of the corrosion and the subsequent deterioration [16], which could recommend high strength concrete as the material choice for sustainable concrete structures. Moreover, the self- 
healing capacity of the high strength concrete due to the subsequent hydration of the binder particles can delay the propagation of the corrosion or even partially regenerate concrete integrity $[17,18,19,20]$.

The current paper studies the performance of structural, reinforced high strength concrete elements exposed to artificial accelerated corrosion compared to non-exposed specimens in terms of flexural capacity and neutral axis depth. The aim is to demonstrate the beneficial uses of high strength concrete in aggressive environments, even when the corrosion process is initiated in the embedded reinforcement.

\section{Experimental program}

\subsection{Concrete and reinforcement}

The testing specimens and the reinforced concrete elements were made with high strength concrete of concrete grade C70 according to [21], with a water/binder ratio of 0.245 . The type of the longitudinal tensile reinforcement was European steel S500 C, whereas the compressed longitudinal and the transversal reinforcement was mild OB37 of local Romanian production. The concrete composition is detailed in Table 1.

Table 1. Concrete composition C70.

\begin{tabular}{|c|c|}
\hline Components & Quantity \\
\cline { 2 - 2 } Portland Cement CEM I 52.5R & $\mathbf{( K g / \mathbf { m } ^ { 3 } ) ; ( \mathbf { l } / \mathbf { m } ^ { 3 } )}$ \\
\hline Silica fume & 520 \\
\hline River sand (0-4mm) & 52 \\
\hline Crushed gravel (4-8mm) & 530 \\
\hline Crushed gravel (8-16mm) & 530 \\
\hline$*$ Superplasticizer & 706 \\
\hline$*$ Water & 11.44 \\
\hline
\end{tabular}

The concrete's compressive strength on cubes $\mathrm{f}_{\mathrm{cm} \text {,cube, }}$, the flexural and splitting tensile strength $\mathrm{f}_{\mathrm{ct}, \mathrm{fl}}$ and $\mathrm{f}_{\mathrm{ct}, \mathrm{sp}}$, the secant modulus of elasticity $\mathrm{E}_{\mathrm{cm}}$ were determined at the age of 28 days and are presented in Table 2. The yield strength of the reinforcement $f_{\mathrm{yk}}$ is guaranteed by the manufacturer.
Table 2. Test characteristics of concrete and reinforcement.

\begin{tabular}{|c|c|c|c|c|c|}
\hline \multirow{2}{*}{\multicolumn{4}{|c|}{$\begin{array}{l}\text { Concrete } \\
\text { C70 }\end{array}$}} & \multicolumn{2}{|c|}{ Reinforcement } \\
\hline & & & & $\mathrm{S} 500 \mathrm{C}$ & OB37 \\
\hline \multicolumn{4}{|c|}{$\begin{array}{c}\text { Mechanical properties } \\
{[\mathrm{MPa}]}\end{array}$} & \multicolumn{2}{|c|}{$\begin{array}{c}\text { Yield strength } \\
{[\mathrm{MPa}]}\end{array}$} \\
\hline$f_{c m}$,cube & $\mathrm{f}_{\mathrm{ct}, \mathrm{fl}}$ & $\mathrm{f}_{\mathrm{ct}, \mathrm{sp}}$ & $\mathrm{E}_{\mathrm{cm}}$ & \multicolumn{2}{|c|}{$f_{y k}$} \\
\hline 93.9 & 9.60 & 6.95 & 46905 & 500 & 255 \\
\hline
\end{tabular}

\subsection{Reinforced concrete elements}

The experimental study consisted in testing two types of beams:

- Type a - Non exposed elements, tested to failure

- Type b - Pre-cracked to a service limit state, exposed to accelerated corrosion, and then tested to failure

The characteristics of the reinforced concrete elements, such as element ID, cross section $\mathrm{b} \times \mathrm{h}$, concrete cover "c" and the type of element are detailed in Table 3.

Table 3. Characteristics of the reinforced concrete elements.

\begin{tabular}{|c|c|c|c|}
\hline ID & $\mathbf{b} \times \mathbf{h}[\mathbf{m m}]$ & $\mathbf{c}[\mathbf{m m}]$ & Type \\
\cline { 1 - 3 } GDA 1-1 & $125 \times 125$ & 25 & \multirow{2}{*}{ a } \\
\cline { 1 - 2 } GDA 1-2 & $125 \times 125$ & 25 & \\
\cline { 1 - 2 } GDA 2-2 & $125 \times 150$ & 50 & \multirow{2}{*}{$\mathrm{b}$} \\
\cline { 1 - 2 } GDS 1-1 & $125 \times 125$ & 25 & \\
\cline { 1 - 2 } GDS 1-2 & $125 \times 125$ & 25 & \\
\cline { 1 - 2 } GDS 2-2 & $125 \times 150$ & 50 \\
\hline
\end{tabular}

The beams were different in concrete cover and crosssection, but equal at design bending capacity (same reinforcement and effective depth). In order to accelerate the artificial corrosion effects, type b elements were loaded and cracked to a maximum crack width of 0.1 $\mathrm{mm}$ before the corrosion test. The pre-cracking of the elements is designed to facilitate the corrosion process and extensive crack width analysis is performed in previous scientific articles. All elements were tested to failure.

\subsection{Loading test}

The specimens used in this study were one-point loading, simply supported reinforced concrete beams, as 
seen in Figure 1. The strains were measured using analogue strain gauges at mid span.
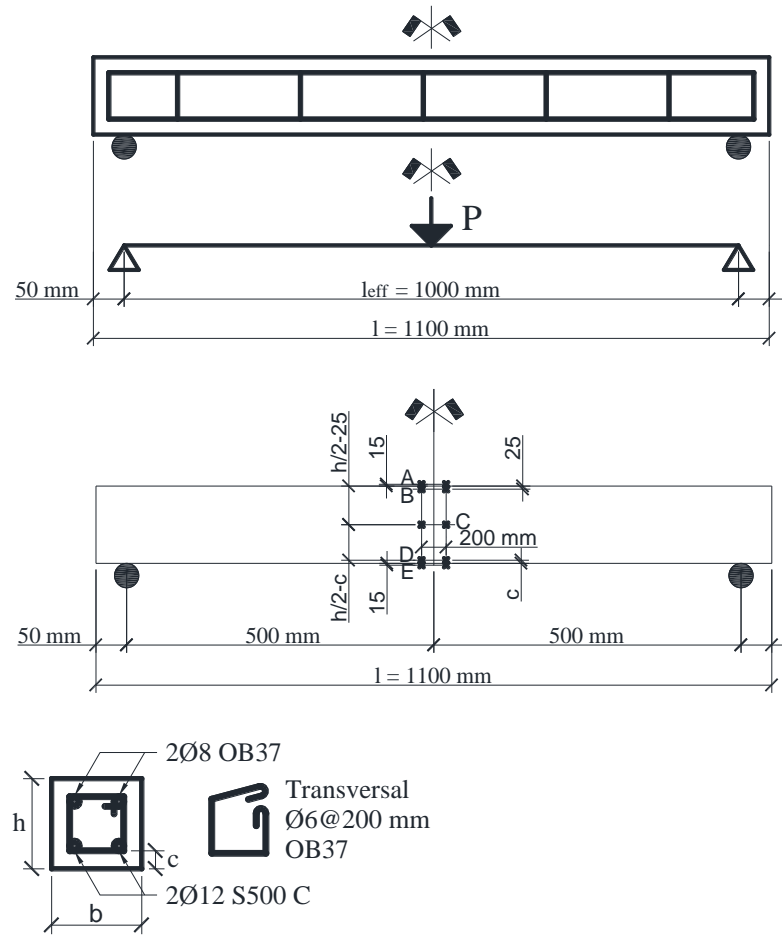

Fig. 1. Reinforcement detailing and set-up test.

\subsection{Accelerated corrosion test}

Simulation of reinforcement corrosion due to environmental actions is a long-term procedure. Therefore, a simplified, more aggressive action was set in place through a process of electrolysis. The set-up for the accelerated corrosion is similar to other research [22]. A schematic view and a picture of the corrosion equipment are presented in Figures 2 and 3.a. The circuit of the electric current generated by an external source consisted of an anode (the embedded reinforcement), the cathode (a stainless-steel plate covering 3 faces of the element) and the electrolyte, a $5 \% \mathrm{NaCl}$ solution. The intensity of the current was set to $3 \mathrm{~mA} / \mathrm{cm}^{2}$ and the elements were exposed for 7 days.

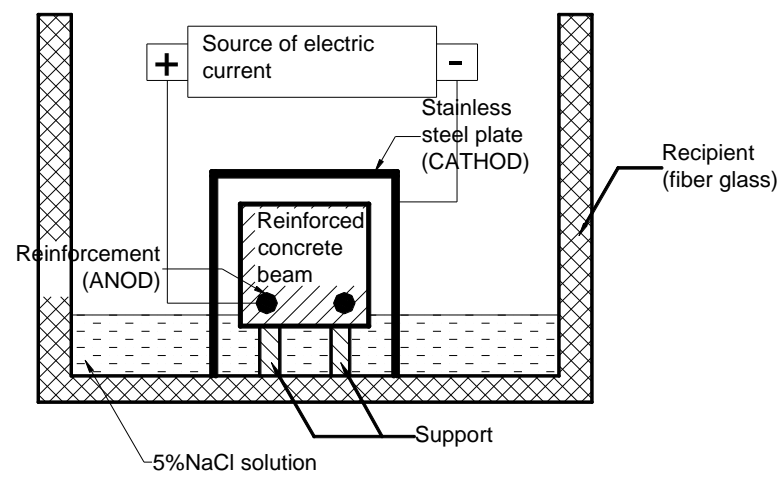

Fig. 2. Schematic view of the corrosion process
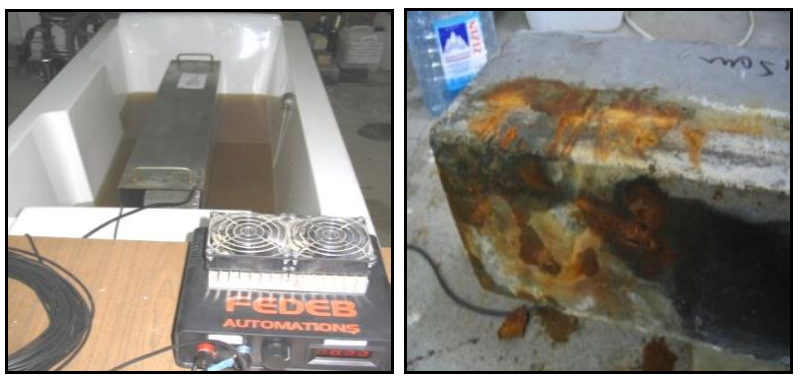

Fig. 3. (a) Corrosion equipment; (b) Visual aspects of a corroded specimen.

Type b elements displayed service limit crack widths of $0.1 \mathrm{~mm}$ when the process of electrolysis started. The cracking state of the elements favours the ingress of the aggressive media in real structures and for the current study, it constituted the path of the electrolyte to the reinforcement. After only 1 day of exposure, the intensity of the electric current dropped under 0.5 $\mathrm{mA} / \mathrm{cm}^{2}$, an indication that the salt bridge of the electrolysis could no longer close the circuit and reach the embedded steel. Moreover, an inspection of the initial cracks immediately after the exposure indicated a light-coloured filling material, which was very likely a mixed cement paste. Although not tested at microscopic level, a process of self-healing due to the un-hydrated cementitious particles in low water/binder compositions might be the source of the filling material. Nevertheless, corrosion took place, as demonstrated by the specific red spots on the surface of the beams (Figure $3 b$ ), but only the transversal reinforcement located in the cracking zone was mainly affected.

\section{Results and discussions}

\subsection{Ultimate versus design bending moments}

Table 4 presents the experimental values recorded during the loading tests of the elements with concrete cover $\mathrm{c}=25 \mathrm{~mm}$ and $\mathrm{c}=50 \mathrm{~mm}$. The bending design capacity $\mathrm{M}_{\mathrm{Rd}}$ was also calculated, using common design equilibrium equations, with high strength concrete coefficients $\eta=0.895$ and $\lambda=0.748$, as in relations (3.20) and (3.22), EC2 [21]. Safety coefficients for concrete $\left(\gamma_{\mathrm{c}}=1.5\right)$ and steel $\left(\gamma_{\mathrm{s}}=1.15\right)$ are also taken into consideration. The characteristic compressive strength was $\mathrm{f}_{\mathrm{ck}}=71 \mathrm{MPa}$.

The corrosion of the reinforcement has little effect on the bending capacity of reinforced high strength concrete beams. The average ultimate bending moment $\mathrm{M}_{\mathrm{u}}$ for beams with concrete cover of $25 \mathrm{~mm}$ is $2.47 \%$ higher for beams type a than for beams type b. However, less than $5 \%$ in experimental testing could usually be allowed, due to execution procedures or minor differences in the material properties and not solely to the influence of the corrosion process. This hypothesis is also confirmed on $50 \mathrm{~mm}$ concrete cover beams, which present an inversed percentage: type $b$ ultimate moment $\mathrm{M}_{\mathrm{u}}$ is higher than type a with $2.13 \%$. 
Table 4. Bending moment - design and ultimate.

\begin{tabular}{|c|c|c|c|c|c|c|}
\hline \multirow{2}{*}{} & \multicolumn{4}{|c|}{$\mathbf{c = 2 5} \mathbf{~ m m}$} & \multicolumn{2}{c|}{$\mathbf{c = 5 0 ~} \mathbf{~ m m}$} \\
\cline { 2 - 7 } & \multicolumn{2}{|c|}{ Type (a) } & \multicolumn{2}{c|}{ Type (b) } & $\begin{array}{c}\text { Type } \\
\text { (a) }\end{array}$ & $\begin{array}{c}\text { Type } \\
\text { (b) }\end{array}$ \\
\cline { 2 - 7 } & $\begin{array}{c}\text { GDA } \\
\mathbf{1}\end{array}$ & $\begin{array}{c}\text { GDA } \\
\mathbf{1 - 2}\end{array}$ & $\begin{array}{c}\text { GDS } \\
\mathbf{1 - 1}\end{array}$ & $\begin{array}{c}\text { GDS } \\
\mathbf{1 - 2}\end{array}$ & $\begin{array}{c}\text { GDA } \\
\mathbf{2 - 2}\end{array}$ & $\begin{array}{c}\text { GDS } \\
\mathbf{2 - 2}\end{array}$ \\
\hline $\begin{array}{c}\mathbf{M}_{\mathbf{R d}} \\
(\mathbf{k N m})\end{array}$ & 8.32 & 8.32 & 8.32 & 8.32 & 8.32 & 8.32 \\
\hline $\begin{array}{c}\mathbf{M}_{\mathbf{u}} \\
(\mathbf{k N m})\end{array}$ & 16.50 & 14.55 & 15.37 & 14.92 & 13.80 & 14.10 \\
\hline
\end{tabular}

Figure 4 presents the difference between the design resistant bending moment $\mathrm{M}_{\mathrm{Rd}}$ and ultimate experimental bending moment of both $25 \mathrm{~mm}$ and $50 \mathrm{~mm}$ concrete cover beams. It can be seen that all the beams, even the corroded ones, display a strength reserve of 39 to $45 \%$ up to failure.

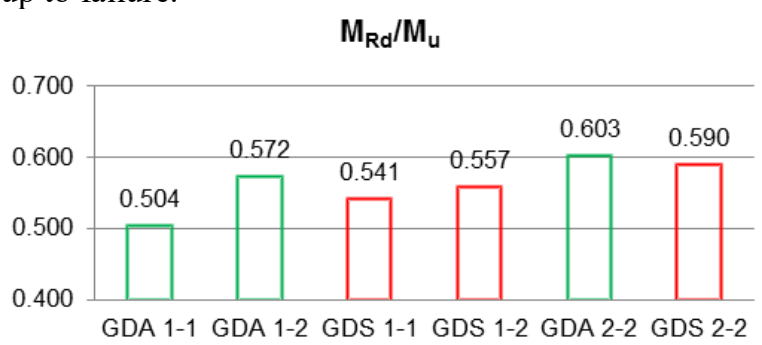

Fig. 4. Ultimate versus design bending moments of nonexposed and exposed beams.

The inverse ratio $M_{u} / M_{R d}$ gives a significant safety factor for the beams: for $25 \mathrm{~mm}$ concrete cover, an average of 1.86 for non-exposed elements, type a, between the ultimate experimental and the design bending moments and an average of 1.82 for exposed elements, type b. For $50 \mathrm{~mm}$ concrete cover, the differences are lower than for $25 \mathrm{~mm}$ concrete cover, due to the brittleness of the concrete cover when cracked: 1.66 for type a and 1.69 for type $b$.

\subsection{Neutral axis depth analysis}

The neutral axis position was constructed based on the strain gauges readings at all loading stages for each beam. The behaviour of the beams in terms of $\mathrm{x} / \mathrm{d}$ ratio (neutral axis depth / effective depth) of the cross section, was assessed at the load level that initiated the yielding of the reinforcement.

Therefore, the longitudinal tensile reinforcement was extracted from type $b$ beams, inspected for signs of corrosion and weight loss and tested for tensile force. No weight loss was recorded, although occasional red, corrosion like spots appeared, mainly at the point of contact with the stirrups. As seen in Figure 5, the yielding started at a stress of about $\sigma=580 \mathrm{MPa}$ and based on the conventional modulus of elasticity of the steel $\mathrm{E}_{\mathrm{s}}=200000 \mathrm{MPa}$, the yielding strain $\varepsilon_{\mathrm{y}}$ was determined $2.9 \%$.

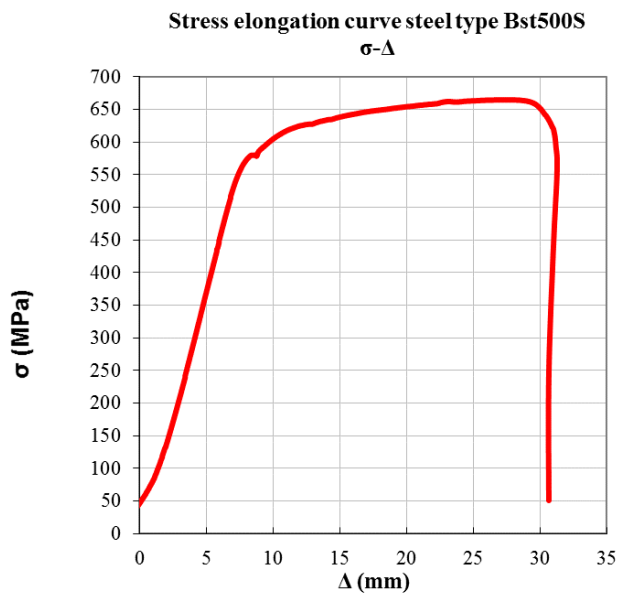

Fig. 5. Steel stress - elongation curve for S $500 \mathrm{C}$

Furthermore, ductility requirements in the ultimate limit state design are that the reinforcement should reach the yielding strain $\varepsilon_{y d}$ in the tension zone and the ultimate compression strain $\varepsilon_{\text {cu2 }}$ in the compression zone at the same time, as seen in Figure 6. The ductility equations for high strength concrete and S500 C tensile reinforcement considering Figure 6, Eurocode 2 [23] and fib Model Code 2010 [21] values are:

$$
\begin{aligned}
& \left(\frac{x}{d}\right)_{\text {design }}=\frac{\varepsilon_{c u 2}}{\varepsilon_{c u 2}+\varepsilon_{y d}}=0.554 \\
& \varepsilon_{y d}=\frac{f_{y k} / \gamma_{s}}{E_{S}}=0.00217 \\
& \varepsilon_{\mathrm{cu} 2}=0.0027
\end{aligned}
$$

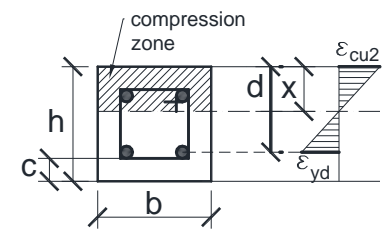

Fig. 6. Ultimate limit state strain diagram.

Figures 7 and 8 present the strain diagrams for a yielding point of the tensile reinforcement when it reaches the yielding point of $2.9 \%$, or in very close proximity. Displacements of the strain gauges occurred for beam type (a) GDA1-1 and thus invalid measurements were recorded. GDA1-1 was therefore dismissed from further comparisons. 
Strain diagram $-\mathrm{c}=25 \mathrm{~mm}$

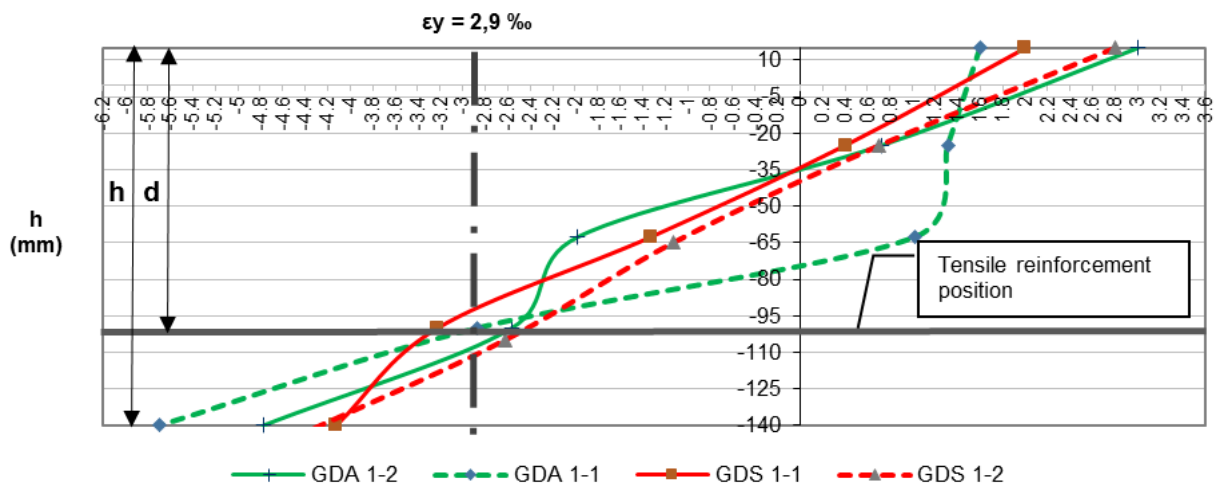

Fig. 7. Neutral axis depth in strain diagrams for beams with $25 \mathrm{~mm}$ concrete cover.

Strain diagram - $\mathrm{c}=\mathbf{5 0} \mathrm{mm}$

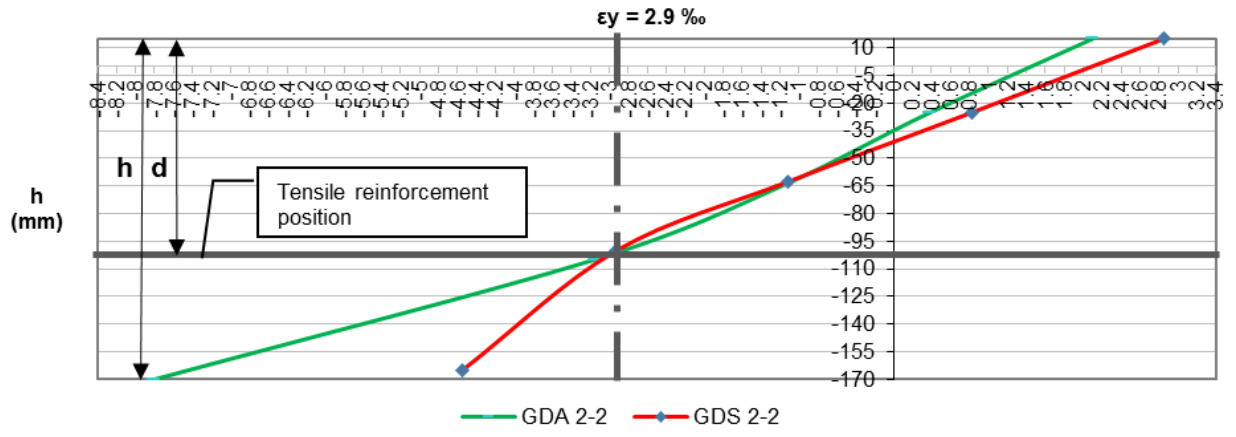

Fig. 8. Neutral axis depth for beams with $50 \mathrm{~mm}$ concrete cover.

Figure 9 displays the experimental value of the $(x / d)$ ratio for each beam along with the design value. Figure 10 shows a general graphic representation of the experimental and design strain deformations. It can be seen that the beams are in the range of $0.67-0.79$ of the design limitations, confirming the safety percentages are met for the resistant bending moment. Furthermore, the corroded beams presented slightly higher $(\mathrm{x} / \mathrm{d})$ ratios, with approximately $13 \%$ in the case of $25 \mathrm{~mm}$ concrete cover and $15 \%$ in the case of the $50 \mathrm{~mm}$. Although the longitudinal tensile reinforcement was not affected by corrosion, the transversal reinforcement presented corrosion pitting, acting like a sacrificial anode. The resulted products filled the existing cracks, putting an additional stress on the crack walls, thus increasing their width and the deformation of the reinforced concrete elements, as expressed by higher (x/d) ratios. Even so, the corroded elements still possess significant residual flexural strength and deformability. These results can be very important in designing reinforced high strength concrete structures in harsh environments.

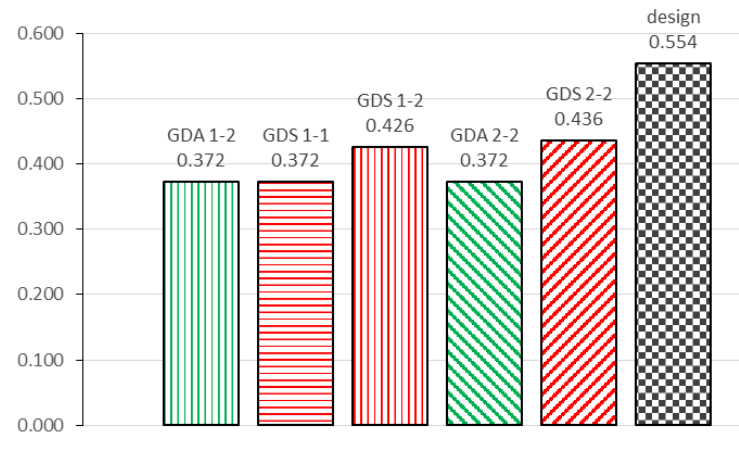

Fig. 9. Type $a$ and $b$ beams (GDA1-1 dismissed): (x/d)exp vs. $(\mathrm{x} / \mathrm{d})_{\text {design }}$

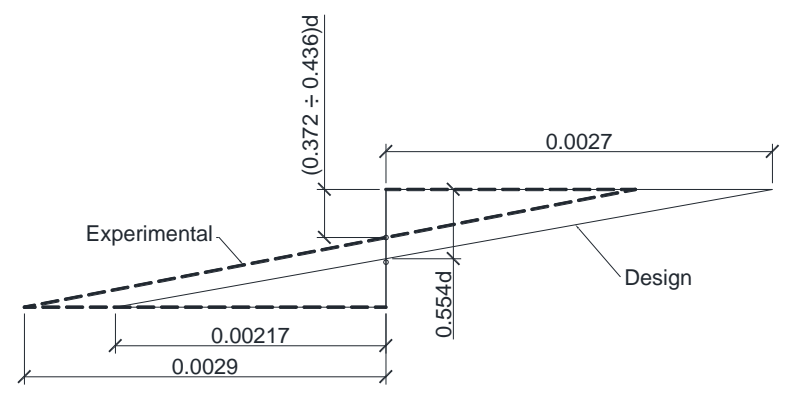

Fig. 10. Experimental and design strain diagram 


\section{Conclusions}

Corrosion of the embedded reinforcement leads to serious deterioration of reinforced concrete elements, such as flexural and shear degradation, with a significant financial impact due to maintenance and repair measurements.

This paper studied the bending moment and neutral axis depth of reinforced high strength concrete elements, with $25 \mathrm{~mm}$ and $50 \mathrm{~mm}$ concrete cover, pre-cracked to a service limit state and then exposed to accelerated corrosion, in comparison to non-exposed elements. These are the main findings of the study:

- The intensity of the applied electrical current significantly decreased after one day of exposure due to the obstruction of the electrolyte's pathway through the structural cracks with a concrete selfgenerated filling material. However, a prolonged exposure could clear up the cracks and re-establish the initial current intensity, which will be the focus of further studies.

- The longitudinal reinforcement was not affected by corrosion;

- The transversal reinforcement intersected by bending cracks was affected by pitting corrosion. Occasional red spots on the surface of the elements also appeared in other areas;

- Ultimate bending capacity was above the design load, with an average of $39 \%$ for corroded beams and $45 \%$ for non-exposed beams;

- The ultimate bending moments of the exposed and non-exposed beams were within a range of $3 \%$ for both $25 \mathrm{~mm}$ and $50 \mathrm{~mm}$ concrete covers;

- The experimental (x/d) ratios of all the beams were in the range of $0.67 \div 0.79$ of the design ratio;

- $\quad$ The corroded beams presented slightly higher $(\mathrm{x} / \mathrm{d})$ ratios, with approximately $13 \%$ in the case of 25 $\mathrm{mm}$ concrete cover and $15 \%$ in the case of the 50 $\mathrm{mm}$ than non-exposed beams;

Based on the research results, the corroded reinforced high strength concrete elements possessed significant residual flexural strength and deformability. Using high strength concrete in aggressive environments can be beneficial for extended structural service life. However, a continuation of the study is in order for the evaluation of the self-healing capacity of the high strength concrete, a complete mapping of the stirrup corrosion and the influence of the service cracks or concrete defects on the structural behaviour in harsh environments.

\section{References}

1. European Standard "Concrete --Part 1: Specification, performance, production and conformity", EN 206-1

2. S. Yoon, K. Wang, W. J. Weiss, et al., ACI Mat. J. 97(6) (2000)

3. W. Li, W. Liu, S. Wang, Adv. in Mat. Sc.\& Eng. (2017), 11 pg, ID 3968578
4. A. Blagojevic, D.A. Koleva, J.C. Walraven, XIII Conf. On Durab. of Build. Mat. And Comp., 834841, (2014)

5. F. Chuanqing, J. Nanguo, et al., Corrosion Science 117, 11-23 (2017)

6. K. A. Mokhtar, J. M. Loche, et al, Report no. 2-2. Concrete in marine environment, MEDACHS, Interreg IIIB Atlantic Space - Project no. 197 (2006)

7. L. Chung, H. Najm, et al., Cement \& Concrete Composites 30, 184-193 (2008)

8. F. Jnaid, R. S. Aboutaha, Eng Struct. 119, 198-216 (2016)

9. Y. Liu, N. Jiang, et al., Constr. and Build. Mat. 117, 302-310 (2016)

10. A. Phetkaysone, T. Ishida, et al., Concrete Durability and Service Life Planning ConcreteLife'09, RILEM Pub. SARL, 55 - 62 (2009)

11. Y-C. Ou, N. Dang, Eng. Struct. 126, 210-223 (2016)

12. W. Zhu, R. François, Constr. and Build. Mat. 51, 461-472 (2014)

13. Z-H. Lu, Y-B. Oua, et al., Constr. and Build. Mat. 127, 293-305 (2016)

14. A. K. El-Sayed, Constr. and Build. Mat. 134, 176184 (2017)

15. A. S. Al - Harthy, J. Mullard, et al.,, CONSEC'07 Tours France, Vol. 1, 383 - 390 (2007)

16. A. N. Sanchez, A. A. Sagues, et al., RILEM Int. workshop on performance-based specification and control of concrete durability, $533-540$

17. A. Castel, T. Vidal, et al., CONSEC'07 Tours France, Vol. 1 (2007)

18. M. Sahmaran, M. Li, et al., ACI Mat. J. 104 (6), (2007)

19. V. Baroghel - Bouny, P. Rougeau, et al., Bulletin des Laboratoires des Points et Chaussées 217, 75 84 (1998)

20. P. C. Aitcin, E\&FN SPON, ISBN: 0419192700, (1998)

21. fib Bulletin 55, Model Code 2010, ISSN 1562-3610, ISBN 978-2-88394-095-6

22. A. K. Azad, S. Ahmad, et al., ACI Mat. J., 104(1), (2007)

23. European Standard, "Eurocode 2: Design of concrete structures - Part 1-1 : General rules and rules for buildings", EN 1992-1-1 